\title{
Potential Influence of Endothelial Adsorption on the Delayed Time to Maximum Concentration of Biopharmaceuticals
}

\author{
Joannes A. A. Reijers ${ }^{1,2}$ - Martijn J. C. Dane ${ }^{3}$ Anton Jan van Zonneveld ${ }^{3}$. \\ Jacobus Burggraaf ${ }^{1} \cdot$ Matthijs Moerland ${ }^{1}$
}

Published online: 9 August 2017

(C) The Author(s) 2017. This article is an open access publication

\begin{abstract}
Background and objectives Maximum plasma concentration of biopharmaceuticals sometimes occurs long after completion of intravenous infusion. The objective of this research was to study the hypothetical adsorption of biopharmaceuticals to endothelium and infusion material, which may theoretically explain this phenomenon.

Methods Infusion procedures were mimicked in an artificial vessel covered with a confluent monolayer of endothelial cells. Three monoclonal antibodies (MAbs) and $\mathrm{C} 1$ inhibitor were studied.

Results Adsorption of MAbs to endothelium was observed followed by release when the vessel was subsequently perfused with buffer. Adsorption to infusion material also occurred to various degrees and in a seemingly random fashion, with a loss of up to $15 \%$ during a single flush of the line, but release from the line was not seen.

Conclusions Our results indicate that adsorption of biopharmaceuticals to endothelium can occur. This observation can explain the increase in plasma concentration after completion of intravenous administration.
\end{abstract}

Joannes A. A. Reijers

jreijers@chdr.nl

1 Centre for Human Drug Research (CHDR), Zernikedreef 8, 2333 CL Leiden, The Netherlands

2 Department of Rheumatology, Leiden University Medical Center, Leiden, The Netherlands

3 Department of Internal Medicine (Nephrology) and the Einthoven Laboratory of Experimental Vascular Medicine, Leiden University Medical Center, Leiden, The Netherlands

\section{Key Points}

The time to maximum concentration $\left(t_{\max }\right)$ of biopharmaceuticals can occur long after completion of intravenous administration.

The monoclonal antibodies trastuzumab and bevacizumab adsorb to endothelial cells within an artificial vessel, and are subsequently released when the luminal concentration is lowered. This finding can theoretically explain the increase in plasma concentration after completion of intravenous administration.

Flushing of the infusion lines to complete administration of a biopharmaceutical does not result in a greater quantity of biopharmaceuticals being administered during flushing than what would be expected. Thus, flushing the infusion line does not contribute to the delay in the $t_{\max }$.

\section{Introduction}

Basic pharmacokinetic principles teach that for the intravenous (IV) route of administration, the maximum plasma concentration $\left(C_{\max }\right)$ is reached at the end of the infusion (EOI). In other words, the time to $C_{\max }\left(t_{\max }\right)$ equals the infusion duration, with a margin of a few minutes, as it is understood that the administered drug requires a finite time to travel to the sampling site. Sufficient evidence exists, however, that this may not always be true. Table 1 provides examples of drugs for which a delayed $t_{\max }$ after IV administration has been described. 
Table 1 Drugs with a delayed $t_{\max }$

\begin{tabular}{|c|c|c|c|c|c|}
\hline Drug product & EOI (h) & $t_{\max }(\mathrm{h})$ & $C_{\max } / C_{\mathrm{EOI}}(\%)$ & PK samples (h) & References \\
\hline$\alpha 1$-Antitrypsin & $(0.25)$ & $0.7^{\mathrm{a}}, 1.5^{\mathrm{a}}$ & & & [1] \\
\hline Bevacizumab & 0.67 & 3.00 & 123,134 & $0.67,0.83,1,2,3,4,5$ & Data on file \\
\hline \multirow[t]{3}{*}{$\mathrm{C} 1$ inhibitor } & Bolus & $0.5,1.0$ & & $0.25,0.5,0.75,1,2$ & {$[2]$} \\
\hline & $(0.17)$ & $2.7^{\mathrm{a}}, 3.9^{\mathrm{a}}$ & & & [3] \\
\hline & 0.13 & $0.42^{\mathrm{a}}, 0.60^{\mathrm{a}}$ & & $0.25,0.5,1,2$ & Data on file \\
\hline \multirow[t]{2}{*}{ Cetuximab } & 1 & $2,7.9$ & & $2,5,8$ & [4] \\
\hline & 1 & $3.00,3.63,3.75,4.00$ & & 1,4 & {$[5]$} \\
\hline Dalotuzumab & 2 & $3.5,5$ & 117 & $2,5,8$ & [4] \\
\hline Glucarpidase & 0.08 & $0.25,0.55$ & & $0.08,0.25,0.5,1,2$ & {$[6]$} \\
\hline Pembrolizumab & 0.5 & $1.2,4.0$ & & $\sim 0.5,6 \pm 2$ & [7] \\
\hline \multirow[t]{3}{*}{ Pertuzumab } & 0.5 & 1.8 & & & [8] \\
\hline & 0.5 & 5.5 & & & [9] \\
\hline & 1.5 & 3.2 & & $1.75,3,5.5,9.5$ & {$[10]$} \\
\hline Ramucirumab & (1) & $1.15^{\mathrm{b}}$ & & $1,1.5,2$ & [11] \\
\hline \multirow[t]{4}{*}{ Trastuzumab } & 1.5 & $1.7^{\mathrm{a}}, 2.7^{\mathrm{a}}, 4.4^{\mathrm{a}}$ & & $1.5,3,4,6$ & [12] \\
\hline & 1.5 & $3.46^{\mathrm{a}}$ & 113 & $1.5,2,3,4,6$ & [13] \\
\hline & 1.5 & $1.65,3.00$ & & $1.5,3,6$ & [14] \\
\hline & 1.5 & $2.083^{\mathrm{a}}, 2.303^{\mathrm{a}}, 2.674^{\mathrm{a}}, 2.683^{\mathrm{a}}, 3.096^{\mathrm{a}}$ & $(113,124,129,132,141)$ & $1.5,2,3,4,5,6,8$ & [15] \\
\hline
\end{tabular}

Values are expressed as median unless stated otherwise. In case more than one value is given for $t_{\max }$ or $C_{\max } / C_{\mathrm{EOI}}$, multiple (combination) treatments or treatment regimens (e.g., dosing interval or dosage) are presented in the reference, or parameters were obtained during multiple treatment cycles, each with a different value. Numbers in parentheses are not reported in the reference but derived from the package insert

$C_{m a x} / C_{E O I}$ ratio of maximum plasma concentration over concentration at EOI, based on reported averages, EOI end of infusion, equals infusion duration, $P K$ samples scheduled collection time of post dose pharmacokinetic plasma samples, $t_{\max }$ time to maximum plasma concentration $\left(C_{\max }\right)$

${ }^{\text {a }}$ Mean

b Geometeric mean

Although this list is not exhaustive, the phenomenon seems to be limited to (poly)peptides, in particular monoclonal antibodies (MAbs), for which differences of several hours have been reported between $t_{\max }$ and EOI. Although noted and reported, it appears that not much attention has been given to this observation, let alone an explanation.

Based on the reported findings, we considered two hypotheses to explain the findings. First, the drug product may aggregate in the infusate because of the relatively high concentration, which is followed by disaggregation when diluted in plasma upon administration, assuming that the bioassay is unable to measure aggregates. We consider this to be unlikely as protein aggregation is often irreversible. Even if the aggregation were reversible, the physical conditions in the human body determining the equilibrium would not change over time [16-18]. Moreover, it is common practice to tightly control the fraction of drug aggregates below $5 \%$, because of adverse reactions, which seems incompatible with the observed increases in plasma concentration after EOI exceeding 10\% (Table 1).

The second hypothesis is that the drug substance is bound to and released from the vessel wall or taken up and released by endothelial cells (ECs), particularly in the presence of a high local concentration at the infusion site. After EOI, the concentration drops, and drug substance is released from the wall or by the cells, causing a rise in plasma concentration and hence a delayed $t_{\max }$. Adsorption to or absorption by circulating blood constituents may also occur, although it is less likely to affect the plasma concentration over time, as these components follow the same route as the infused substance, travelling from a high concentration (infusion site) to a low concentration (sampling site).

Infusion lines are sometimes flushed with normal saline to also administer the line content, which is usually done to save the cost of additional (non-administrable) drug product. If — by analogy — binding of a biopharmaceutical to an IV line occurs during the first part of the administration procedure, and the adsorbed fraction is released during flushing, the flushing solution contains drug product as well. Flushing an IV line may thus result in a continuation of administration of a biopharmaceutical after the anticipated EOI and hence an apparent delay in $t_{\max }$.

The objective of this study was to find support for the second hypothesis by mimicking the administration procedure on a small scale with therapeutic proteins. These form the largest class of the so-called biotechnology- 
derived products', also commonly known as biopharmaceuticals. Specifically, it was investigated whether biopharmaceuticals could bind to or be taken up by ECs and be subsequently released. In addition, potential adsorption to IV lines during administration followed by desorption during flushing was studied.

Large polypeptides distribute slowly to the extravascular compartment because of their size [19], which results in a relatively stable plasma concentration during and shortly after infusion. By focussing on drug products in that category, the need to consider tissue distribution in the experiments was eliminated. Comparison to a negative control was sought; however, to the best of our knowledge, a MAb or other large therapeutic protein with a known $t_{\max }$ at EOI does not exist. To further complicate this search, the $t_{\max }$ of intravenously administered proteins is only infrequently reported as is the pharmacokinetic sample density in clinical trials.

\section{Methods}

\subsection{Biopharmaceuticals}

For this experiment, three registered biopharmaceuticals were chosen from Table 1, namely bevacizumab $\left(\right.$ Avastin $\left.{ }^{\circledR}\right)$, trastuzumab $\left(\right.$ Herceptin $\left.^{\circledR}\right)$, and $\mathrm{C} 1$ inhibitor $\left(\right.$ Berinert $\left.^{\circledR}\right)$, and one experimental $\operatorname{IgG1}$. These drug products were reconstituted by the Pharmacy of Leiden University Medical Center (LUMC) according to the manufacturer's instruction, with one exception. For the higher concentrations of $\mathrm{C} 1$ inhibitor, less dissolvent was used, as reconstitution in the prescribed $10 \mathrm{~mL}$ water for injection resulted in a concentration of $4 \mathrm{mg} / \mathrm{mL}$. The experimental human $\operatorname{IgG} 1$ was only available diluted in $0.9 \% \mathrm{NaCl}$ at $3.75 \mathrm{mg} / \mathrm{mL}$.

\subsection{Cell Cultures (Artificial Vessel)}

All in vitro experiments were performed with human umbilical vein endothelial cells (HUVECs), freshly isolated (by $0.25 \%$ trypsin treatment). Residual umbilical cord blood and umbilical cords obtained as part of regular medical procedures were used anonymously. This 'further use' of non-identifiable human material for scientific research is in accordance with the Dutch law.

After isolation, HUVECs were cultured in EGM2 medium (Lonza, Basel, Switzerland) containing antibiotics and antimycotics (Life Technology, Carlsbad, California, USA), and used for experiments on passage 3-4. To obtain a confluent, quiescent endothelial monolayer that closely resembles the physiological situation, HUVECs were grown under a constant laminar flow of $10 \mathrm{dyne} / \mathrm{cm}^{2}$ for
7 days using a closed perfusion Ibidi flow system (ibiTreat $0.4 \mu$-Slide VI Luer) (Ibidi, Martinsried, Germany). This system is referred to as 'artificial vessel' (AV).

The cells in the AV were exposed to varying concentrations of a single biopharmaceutical in Hank's Balanced Salt Solution (HBSS) with $1 \%$ bovine serum albumin (BSA) (Life Technology) or in EGM2 with 1\% BSA only. Optionally, the AV was pre-treated with $15 \mathrm{U} / \mathrm{mL}$ heparanase III (HPSE) (Sigma-Aldrich, St. Louis, Missouri, USA) to degrade heparan sulphate proteoglycans from the glycocalyx or with increasing concentrations of heparin to examine the role of heparan sulphate proteoglycans on the possible binding of biopharmaceuticals to the AV.

Throughout the experiments, the cell cultures were maintained at $37{ }^{\circ} \mathrm{C}$ and $5 \% \mathrm{CO}_{2}$. All experiments were executed at least twice in duplicate to minimise culture variability and to confirm the validity of the results. The tested biopharmaceutical concentrations were based on the concentrations observed clinically after administration of the standard IV dose of $6 \mathrm{mg} / \mathrm{kg}$ for trastuzumab: $2 \mathrm{mg} / \mathrm{mL}$ (infusate) and $0.2 \mathrm{mg} / \mathrm{mL}\left(C_{\max }\right)$. Because the experimental IgG1 could only be provided as infusion solution $(3.75 \mathrm{mg} / \mathrm{mL}$ in $0.9 \% \mathrm{NaCl})$, this MAb was not included in any of the cell culture experiments.

\subsection{Static Experiments}

HUVECs from the AV were exposed to varying concentrations of biopharmaceuticals for 30 min under static conditions. This exposure could be repeated, each instance with a different concentration to simulate increasing and decreasing concentrations during IV administration. To mimic the in vivo situation following infusion, cells were washed one or more times with HBSS containing 1\% BSA.

\subsection{Dynamic Experiments}

In the dynamic experiments, the AV was perfused with the biopharmaceutical for a predefined period, followed by perfusion with a lower concentration of the same biopharmaceutical, mimicking the situation during and after administration. The experiment was stopped at various time points, and the endothelial monolayer was immediately fixed and imaged. The perfusion rate was $0.2 \mathrm{~mL} / \mathrm{min}$ (effective velocity $0.2 \mathrm{~cm} / \mathrm{s}$ ).

\subsection{Staining and Imagining}

HUVECs (static or dynamic experiments) incubated with different concentrations of biopharmaceuticals were fixed in $4 \%$ paraformaldehyde in HBSS for $10 \mathrm{~min}$ at room temperature, washed twice with $1 \%$ BSA in HBSS, and blocked with 5\% normal goat serum (Dako, Carpinteria, 
California, USA) in HBSS for $30 \mathrm{~min}$. Cultures were incubated for at least $60 \mathrm{~min}$ at $4{ }^{\circ} \mathrm{C}$ with $10 \mu \mathrm{g} / \mathrm{mL}$ TRITC-labelled wheat germ agglutinin (WGA) (SigmaAldrich, 1:100), and Hoechst 33258 (Sigma-Aldrich, 1:5000), diluted in HBSS $+1 \%$ BSA. In the experiments with a MAb, $2 \mu \mathrm{g} / \mathrm{mL}$ of an Alexa488-coupled anti-human-IgG(H $+\mathrm{L}$ ) goat-IgG (Thermo Fisher, Waltham, Massachusetts, USA, 1:500) was included in the incubation. Conversely, in the experiments with $\mathrm{C} 1$ inhibitor, an anti-human-C1 inhibitor rabbit-IgG $(1: 25)$ and a secondary Alexa488-coupled anti-rabbit-IgG-goat-IgG (Thermo Fisher) were included in the incubation. After washing three times with HBSS $+1 \%$ BSA, cells were imaged using a Leica SP5 confocal microscope.

Confocal 12-bit gray-scale axial image stacks (xyz dimensions, $\quad 0.08 \times 0.08 \times 0.13 \mu \mathrm{m}) \quad$ that covered $6724 \mu \mathrm{m}^{2}$ of surface area per image and a height of 5-10 $\mu \mathrm{m}$ above the EC nuclear plane were recorded using the LAS-AF image software (Leica). The image stacks were analysed with the public domain National Institutes of Health IMAGE program [20]. Cross sections of the cell layer were generated using this software. For quantification, the area of interest was selected (to discard staining which accumulated underneath the cell layer in the areas of inadequate cell-cell contacts), and the average signal intensity was measured throughout the whole $x y z$ area of the recorded image stacks.

\subsection{Infusion Profiling}

Infusion procedures were replicated with a standard flexible PVC IV line (CODAN \#43.4270, Santa Ana, California, USA) with an inner diameter of $3.0 \mathrm{~mm}$ that was cut to hold $10.0 \mathrm{~mL}$. The line was coupled via its Luer-Lock adaptor to a syringe that was placed in a calibrated syringe pump (Omnifuse, Graseby Medical Ltd., Watford, UK).

After the lines were filled with the solution containing the biopharmaceutical ('infusate') and allowed to rest for $1 \mathrm{~h}$, the pump was started at a rate of $2 \mathrm{~mL} / \mathrm{min}$. After the IV line was perfused with the infusate at a constant concentration for a predefined period ('perfusion'), the IV line was flushed with $50 \mathrm{~mL} 0.9 \% \mathrm{NaCl}$ (Baxter BV, Utrecht, The Netherlands) at the same rate ('flushing').

The solution coming out of the IV line was sampled every $2.5 \mathrm{~min}$, corresponding to one-half of the line volume. The wash-out from the line between these samples was collected as well.

To determine the effect of infusion rate and concentration on binding characteristics, the rate was varied from 1 to $3 \mathrm{~mL} / \mathrm{min}$ (only for trastuzumab) and the concentration from 1.25 to $10 \mathrm{mg} / \mathrm{mL}$ (all except the experimental IgG1). This covers the range of commonly encountered infusion rates and concentrations for biopharmaceuticals. The dilutions of the biopharmaceuticals in $0.9 \% \mathrm{NaCl}$ (Fresenius Kabi, Schelle, Belgium) were prepared by the LUMC Pharmacy.

All experiments with unique combinations of parameters were performed at least twice.

\subsection{Drug Concentration}

Drug concentration in the samples from the infusion profile was determined at the Central Clinical Chemical Laboratory (CCCL) of the LUMC as total protein concentration with a colorimetric assay (Biuret reaction) on a Cobas P800 module (Roche, Penzberg, Germany). This method was validated against specific immunochemical assays for total human IgG and $\mathrm{C} 1$ inhibitor, performed on a BN-Prospec nephelometer (Siemens, Marburg, Germany). These assays use an antibody against the $\gamma$-chain of human $\operatorname{IgG}$ and antiserum to human $\mathrm{C} 1$ inhibitor, respectively. The lower limit of quantitation (LLOQ) was $0.04 \mathrm{~g} / \mathrm{L}$.

\subsection{Statistical Analysis}

Results are presented as mean (standard deviation, SD) for continuous data and as number (percentage) for categorical data, unless otherwise specified. As this study consisted of multiple hypothesis-generating experiments, no formal inference test was performed.

The cumulative wash-out from the IV lines was calculated as the sum of the biopharmaceutical dose in all the collected samples up to a certain point. The dose per sample was calculated as the product of sample volume and biopharmaceutical concentration in the sample. Samples with a concentration $<$ LLOQ were excluded from the calculation. To estimate the theoretical wash-out, the calculation was repeated with the concentration of the excluded samples ( $<$ LLOQ) assumed to be $0.0394 \mathrm{~g} / \mathrm{L}$.

Data analysis was performed with R (v2.15.2, R Foundation for Statistical Computing, Vienna, Austria, 2012).

\section{Results}

\subsection{Artificial Vessel}

\subsubsection{Static Experiments}

Following incubation of human umbilical cord endothelial cells (HUVECs) with $2 \mathrm{mg} / \mathrm{mL}$ trastuzumab for $30 \mathrm{~min}$, binding to the luminal surface of the HUVECs was observed, co-localising with the WGA signal (binding the carbohydrate $\mathrm{N}$-acetyl galactosamine), whereas in the control samples, the signal of the secondary anti-humanIgG antibody was absent (Fig. 1a, b). Translocation to the 


\section{A}

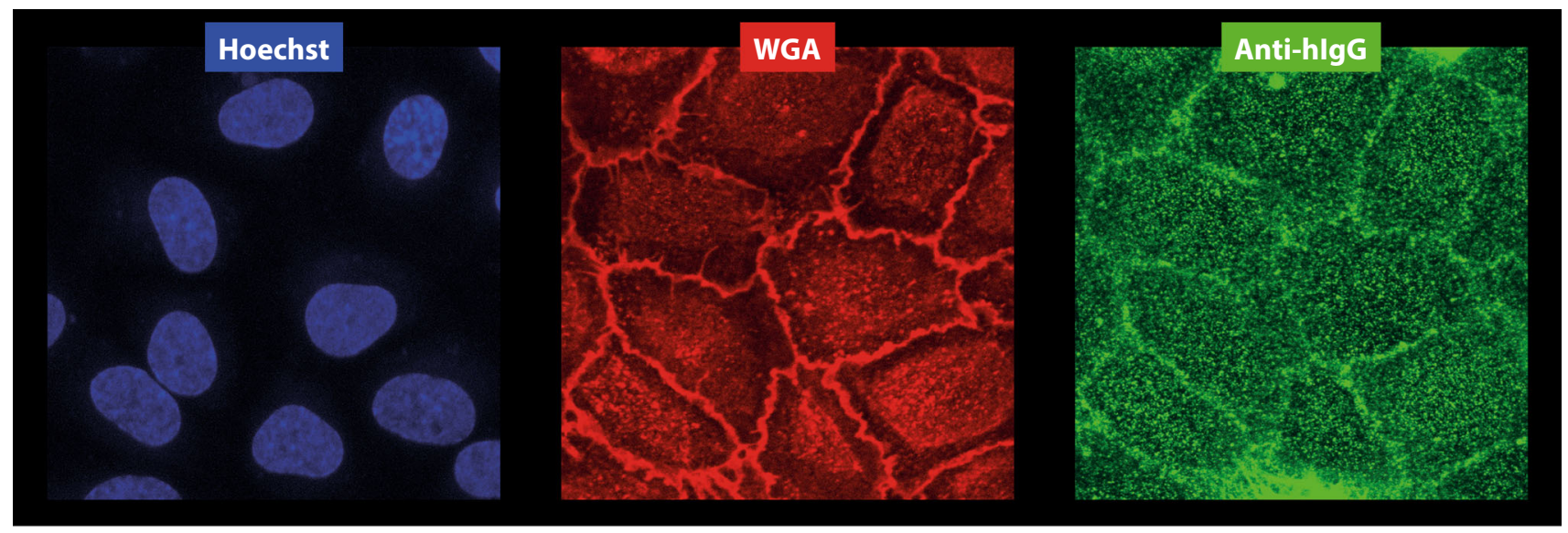

B

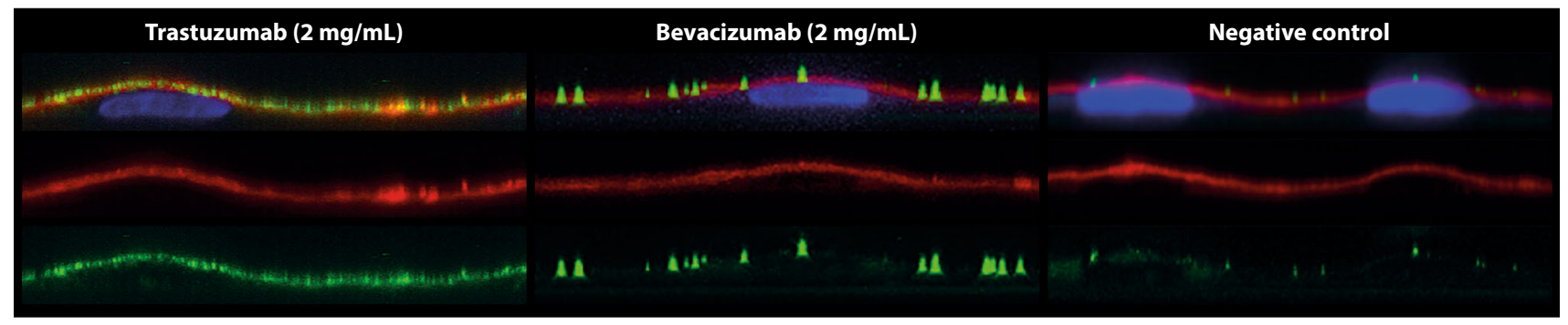

C

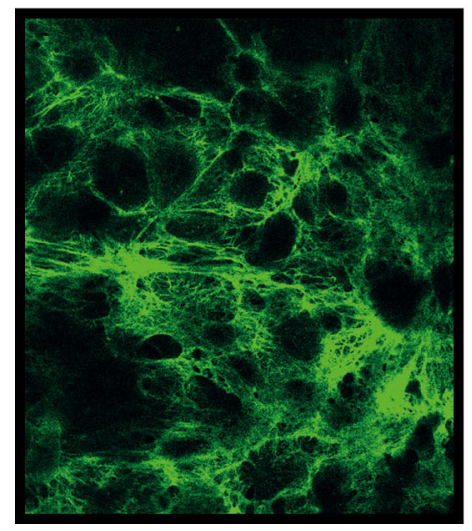

D

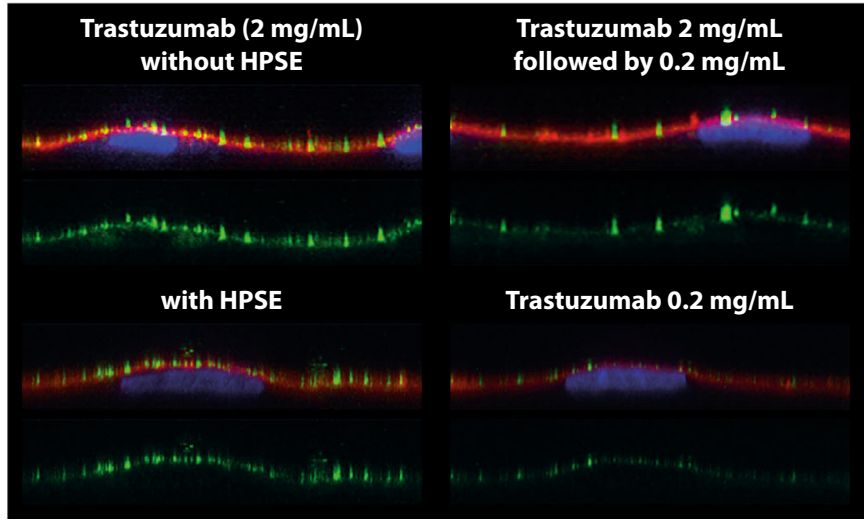

E

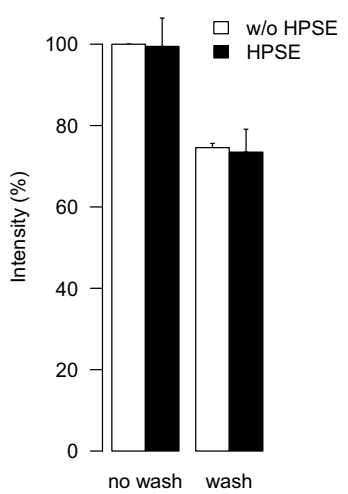

Fig. 1 Static experiments. After perfusion of the artificial vein with $2 \mathrm{mg} / \mathrm{mL}$ trastuzumab or bevacizumab, the human umbilical vein endothelial cells (HUVECs) were stained with Hoechst 33258 (nucleus, blue), TRITC-labelled wheat germ agglutinin (WGA) binding the carbohydrate $\mathrm{N}$-acetyl galactosamine in the glycocalyx (red), and an Alexa488-coupled anti-human-IgG-goat-IgG (green trastuzumab/bevacizumab). Overview (a) and cross section (b) for trastuzumab (a, b) and bevacizumab (b). Where no confluent layer of HUVECs had formed, dense staining of the subcellular matrix

basal side or internalisation by the endothelial cells was not seen, or was negligible in relation to the apical binding, although the experiments were not specifically designed to detect endocytosis. Where the HUVECs had not formed a confluent monolayer, dense staining of the basal layer in a reticular pattern occurred (Fig. 1c). occurred following incubation with $2 \mathrm{mg} / \mathrm{mL}$ trastuzumab (c). Effect of pre-treating the HUVECs with heparanase (HPSE) on binding of $2 \mathrm{mg} / \mathrm{mL}$ trastuzumab (d, e) or washing the HUVECs three times with buffer after incubation with trastuzumab (e). The signal intensity was normalised to the $2 \mathrm{mg} / \mathrm{mL}$ trastuzumab without (w/o) HPSE condition and is displayed as mean $\pm \mathrm{SD}(n=2)$. Perfusing the HUVECs with $2 \mathrm{mg} / \mathrm{mL}$ followed by $0.2 \mathrm{mg} / \mathrm{mL}$ trastuzumab similarly reduced the signal, but not to the level that was observed when the HUVECs were perfused with $0.2 \mathrm{mg} / \mathrm{mL}$ only (d)

Washing the cells with buffer alone or with buffer containing a lower concentration of trastuzumab reduced the signal (Fig. 1d, e). Comparable results were obtained when varying the duration of the initial incubation with trastuzumab, or when exposing and washing under flow or static conditions (data not shown). 
As trastuzumab was recently demonstrated to interact with heparan sulphate proteoglycans [21], a major component of the extracellular glycocalyx, their role in the binding of trastuzumab was investigated by pre-treating the HUVECs with heparanase (HPSE). No difference was found compared to untreated cells (Fig. 1d, e). In addition, escalating concentrations of heparin, which binds competitively to heparan sulphate proteoglycans, did not interfere with the binding of trastuzumab (data not shown).

Bevacizumab was observed to bind to the luminal surface as well, although the pattern differed (Fig. 1b). Whereas binding of trastuzumab was characterised by diffuse surface staining with dispersed clusters of greater signal intensity in a varying degree, exposure to bevacizumab resulted in intense clusters scattered along the surface.

Locating C1 inhibitor after incubation proved extremely difficult, as the antibody used for staining resulted in a nonspecific signal on the entire cell layer. Hence, the question whether $\mathrm{C} 1$ inhibitor adsorbs to endothelium in a similar fashion as the tested MAbs could not be answered.

\subsubsection{Dynamic Experiments}

After perfusion of the artificial vessel with $2 \mathrm{mg} / \mathrm{mL}$ trastuzumab for $5 \mathrm{~min}$, the system was flushed with buffer solution. Imaging of the cells during flushing revealed a decline in apically bound trastuzumab (Fig. 2). After 5 min
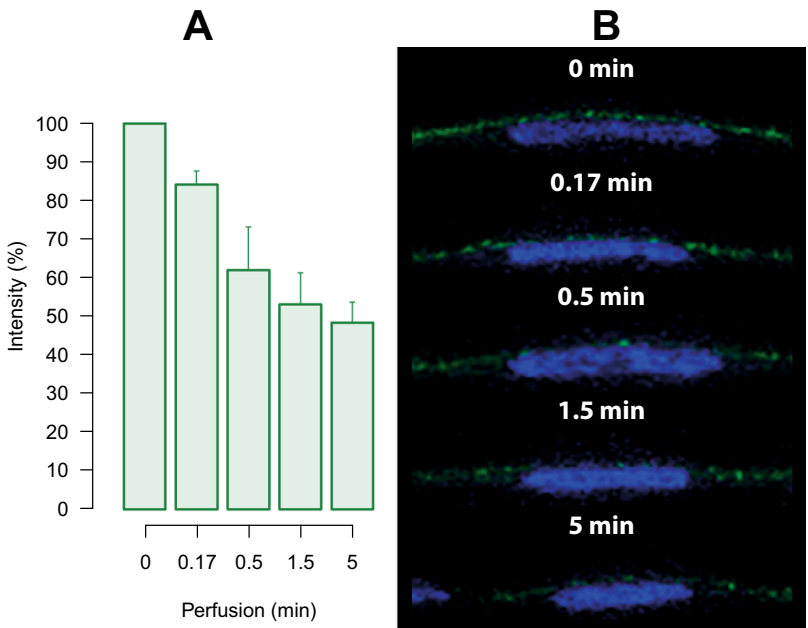

Fig. 2 Dynamic experiments. After perfusing the artificial vein with $2 \mathrm{mg} / \mathrm{mL}$ trastuzumab in culture medium for $5 \mathrm{~min}$ at $0.2 \mathrm{~mL} / \mathrm{min}$, the system was flushed with medium. At this rate, one complete flush of the entire system takes $1 \mathrm{~min}$. At certain moments during the flushing of the artificial vein, the experiment was interrupted and the HUVECs were stained with Hoechst 33258 (nucleus, blue), and an Alexa488-coupled anti-human-IgG-goat-IgG (green trastuzumab): relative Alexa488 signal intensity normalised to baseline $(\mathbf{a}, n=3)$, and representative cross sections of the cell layer $(\mathbf{b})$ of flushing (equalling 5 complete flushes), the luminal signal had decreased to approximately $50 \%$.

\subsection{Infusion Profile}

Replication of infusion procedures indicated an average recovery of approximately $95 \%$ of the anticipated dose at the end of perfusion (similar to the EOI), as well as after flushing the IV line five times (Fig. 3a). During the flushing of the IV lines, the wash-out time-course resembled the theoretical profile of laminar flow. The wash-out profiles for bevacizumab, trastuzumab, the experimental $\operatorname{IgG1}$, and $\mathrm{C} 1$ inhibitor were similar in shape. Introducing an air bubble between the infusate and the flushing solution to prevent diffusion changed the wash-out profile in the direction of plug flow, with no measurable concentration after the IV line was flushed once (Fig. 3b). Flushing the line for longer periods of time did not increase the cumulative wash-out; in all cases, the concentration had dropped $<$ LLOQ (0.04 g/L) after 4 line volumes had been extruded.

A reduced recovery was also observed when pre-filled IV lines were flushed immediately, without the 'perfusion' part of the experiment. Interestingly, this reduction did not always occur. The cumulative wash-out ranged roughly between 70 and $85 \%$ after five flushes, in cases where a reduced outflow was seen, as opposed to the theoretical 95-100\%, even when the potential wash-out in samples with a concentration <LLOQ was taken into account (Fig. 3c). There was no apparent relationship between the cumulative wash-out and the tested drug product. Varying the concentration of the infusate or the perfusion rate had no effect on the results. From Fig. 3c, it may be suggested that a higher concentration or a higher perfusion rate results in a decreased cumulative wash-out. However, such a relationship was not invariably present to allow definite conclusions to be drawn.

\section{Discussion and Conclusion}

The initial experiments with the artificial vessel demonstrated that bevacizumab and trastuzumab adsorb to the luminal surface of endothelial cells, although the observed pattern differed with diffuse staining for trastuzumab and a clustered appearance for bevacizumab. Neither the binding nor the difference could be related to the respective targets of these MAbs. Trastuzumab targets a membrane receptor (HER-2), whereas bevacizumab neutralises a circulating growth factor (VEGF) [22, 23]. HUVECs contain VEGF receptors, but these are not distinctly clustered on the cell surface, and-importantly-bevacizumab inhibits receptor 

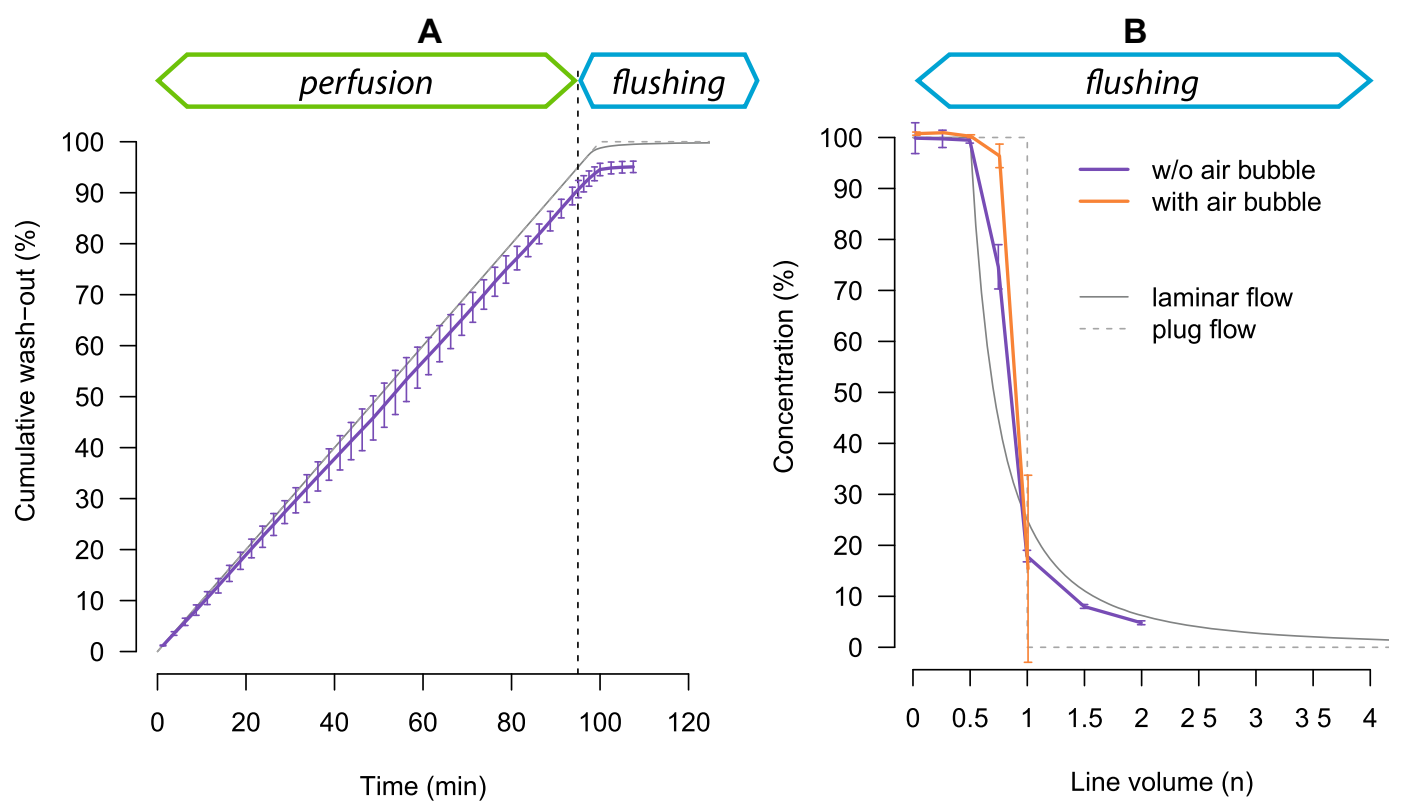

C

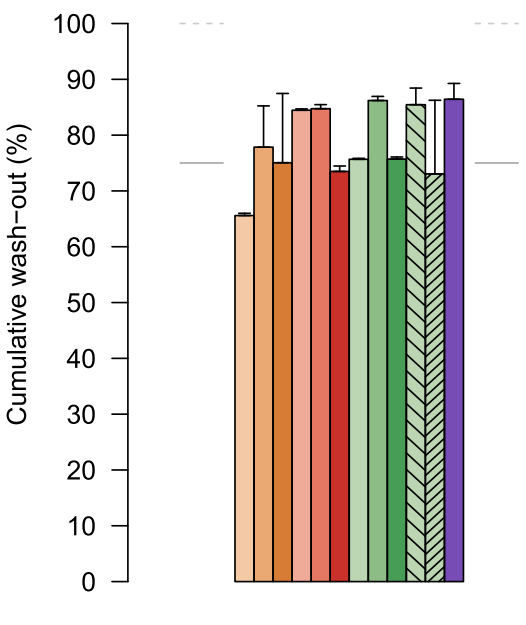

1

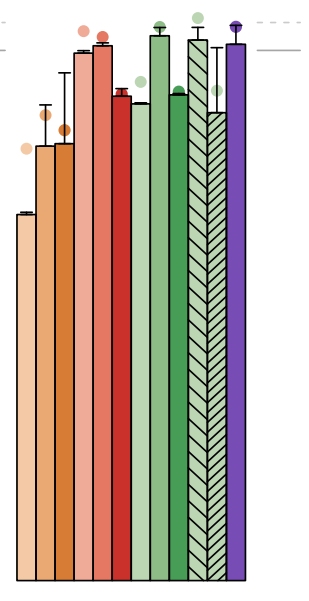

\begin{tabular}{|l}
\hline \\
C1-inhibitor $1.25 \mathrm{mg} / \mathrm{mL}$ \\
C1-inhibitor $2.5 \mathrm{mg} / \mathrm{mL}$
\end{tabular} C1-inhibitor $5 \mathrm{mg} / \mathrm{mL}$ bevacizumab $2.5 \mathrm{mg} / \mathrm{mL}$ bevacizumab $5 \mathrm{mg} / \mathrm{mL}$ bevacizumab $10 \mathrm{mg} / \mathrm{mL}$ trastuzumab $2.5 \mathrm{mg} / \mathrm{mL}$ trastuzumab $5 \mathrm{mg} / \mathrm{mL}$ trastuzumab $10 \mathrm{mg} / \mathrm{mL}$ IgG1 $3.75 \mathrm{mg} / \mathrm{mL}$

$2 \mathrm{~mL} / \mathrm{min}$

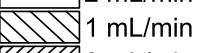

Dllas $3 \mathrm{~mL} / \mathrm{min}$

laminar flow plug flow

Line volume $(n)$

Fig. 3 Infusion profiles. Infusion lines were perfused with a biopharmaceutical ('infusate') for $95 \mathrm{~min}$ at $2 \mathrm{~mL} / \mathrm{min}$ followed by flushing of the line with $0.9 \% \mathrm{NaCl}$ at the same rate until the protein concentration dropped below the lower limit of quantitation (LLOQ) $(0.04 \mathrm{~g} / \mathrm{L})$ (a). Alternatively, the infusion line was filled with a biopharmaceutical and flushed immediately $(\mathbf{b}, \mathbf{c})$. Mean \pm SD cumulative wash-out (b) for an experimental IgG1 $(3.75 \mathrm{mg} / \mathrm{mL})$. Concentration profiles (mean $\pm \mathrm{SD}$ ) with or without (w/o) introducing an air bubble between the infusate and the flushing solution (b). Mean \pm SD cumulative wash-out for different biopharmaceuticals at

engagement by VEGF [24, 25]. Moreover, clustering was also observed for trastuzumab, albeit to a lesser extent.

Although detailed sorption studies were beyond the scope of our investigation, the binding seemed to be concentration-dependent and easily reversible upon washing with a lower concentration, which suggests that the two different concentrations and at different perfusion rates (c). The dots in $\mathbf{c}$ represent the theoretical cumulative wash-out if it is assumed that the samples with a concentration $<$ LLOQ contained a dose of [sample volume $] \times[0.0394 \mathrm{~g} / \mathrm{L}]$. Data are normalised to either the concentration of the infusate or the maximum theoretical wash-out, which equals the total dose added to the system. Results of duplicate experiments are set against the expected wash-out profile assuming laminar or plug flow through the infusion line. The line volume $(n)$ is the number of line volumes $(10.0 \mathrm{~mL})$ passing through the intravenous line during the experiment

biopharmaceuticals were not tightly bound, e.g., to a receptor. The binding of MAbs to the extracellular matrix, where the endothelial barrier had been disrupted, further supports the idea of non-specific binding. In contrast, the finding that the apically located MAb could not be completely washed off (Fig. 2b) suggests a tighter form of 
binding, as does the observation that perfusing the artificial vessel with $2 \mathrm{mg} / \mathrm{mL}$ followed by $0.2 \mathrm{mg} / \mathrm{mL}$ resulted in a higher signal compared to perfusion with $0.2 \mathrm{mg} / \mathrm{mL}$ only (Fig. 1d).

Regardless of the exact nature of the binding, the conclusion that biopharmaceuticals can adsorb to endothelium should not be surprising, as systematic reports on the binding of all kinds of proteins to cell membranes and components of the extracellular matrix date from the $1960 \mathrm{~s}$ [26, 27]. For example, binding of MAbs to extracellular components cause them to be retained upon subcutaneous administration, glycosaminoglycans help to regulate local levels of growth hormones and other signalling factors, and the cellular glycocalyx was found to be a key component for certain protein-cell interactions [28-30].

Electrostatic forces play an important role in the adsorption of proteins. Many contact surfaces in the body are negatively charged, including cell membranes and polysaccharides. In contrast, most MAbs are basic and hence cationic at physiological pH [31]. What is interesting, however, is that one of the natural properties of the glycocalyx is preventing non-specific (protein) adsorption [32]. Biocompatibility research has elucidated some of the principal aspects underlying the interference caused by oligosaccharide (glycocalyx-like) polymers in the adsorption of proteins to negatively charged surfaces. This shows that the flexible hydrophilic chains offer steric hindrance preventing binding of proteins [33, 34]. Such coatings greatly reduce but do not completely prevent adsorption $[35,36]$.

Thus, the local fraction of adsorbed protein is probably small in absolute terms, but with a total endothelium area of 4000-7000 $\mathrm{m}^{2}$ in an adult [37], even minor (local) adsorption to vessel walls can notably affect plasma concentration.

Our findings lend support to the hypothesis of endothelial adsorption. Figure 4 displays (simplistically) how endothelial adsorption can cause a delay in $t_{\max }$. Because of adsorption to the endothelium, the vascular compartment should not be regarded as a well-mixed container. Rather, a gradient exists between areas of high concentration, e.g., the tip of the IV cannula during administration, and areas of low concentration. Upon completion of infusion, the gradient gradually levels off and adsorbed drug product is released in areas where local concentration had previously been high. This increases the measured concentration at the sampling site (Fig. 4d).

Differences in perfusion between tissues may further delay the equilibration over the vascular compartment. Perhaps, the prerequisites for the phenomenon to occur are that the biopharmaceutical is administered continuously over a longer period of time (e.g., as a linear infusion) and that its plasma clearance is relatively slow. This would theoretically allow the build-up of a gradient, especially in lesser perfused tissues.

Staining of C1 inhibitor was unsuccessful, and therefore, adsorption to endothelium could not be ascertained. However, from a theoretical viewpoint, given the generic nature of protein-surface interactions, $\mathrm{C} 1$ inhibitor and the other proteins listed in Table 1 probably behave similarly to the tested MAbs.

It should be noted, however, that our artificial vein is only an approximation of the in vivo situation and does not preclude other mechanisms to contribute to the delay in $t_{\max }$. The human vascular compartment consists of many parallel microcirculations, each with specialised (endothelial) cells, which adds to the complexity of understanding and (pharmacokinetically) modelling the distribution of biopharmaceuticals. Moreover, the plasma concentration profiles over time of biopharmaceuticals also show increases after the (delayed) $t_{\max }$ [38]. Therefore, simple adsorption of biopharmaceuticals to endothelium may only be one of many factors involved in determining plasma concentration. We imagine that an experiment with radiolabelled therapeutic proteins in test animals can be useful to study the distribution over the body during and after intravenous infusion and to validate our findings.

The complexity of the human vasculature is in contrast to the highly controlled experimental conditions of constant laminar flow, temperature, and the use of a single type of endothelial cells (HUVECs) in combination with a particular buffer that contained BSA. The effect of any of these covariates on the results was not studied.

With the exception of the relevance of the presented data to the clinical pharmacologist for determining and interpreting the pharmacokinetic profile of biopharmaceuticals, the clinical relevance is more speculative. This would depend on the exact adsorption site, the tissue where the biopharmaceutical accumulates, and whether it is pharmacologically active there. In addition, the relevance is determined by whether a biopharmaceutical exerts an effect on the endothelium or whether the adsorption to endothelium interferes with a physiological process.

From the wash-out profiles (Fig. 3), it is seen that the bulk delivery of drug through the IV line is governed by convection alone, i.e., transport by the flow of the medium, in this case laminar flow [39]. There may be a blunting effect on the net delivery caused by diffusion of the drug from the infusate (high concentration) into the flushing solution (low concentration), although with an estimated maximum diffusion coefficient derived from the StokesEinstein equation [40] of $7 \times 10^{-5} \mathrm{~mm}^{2} / \mathrm{s}$ for a $105 \mathrm{kDa}$ protein ( $\mathrm{C} 1$ inhibitor) in water at room temperature [41], this effect is negligible compared to the effective fluid velocity of $2.4-7.1 \mathrm{~mm} / \mathrm{s}$ in the IV line. 

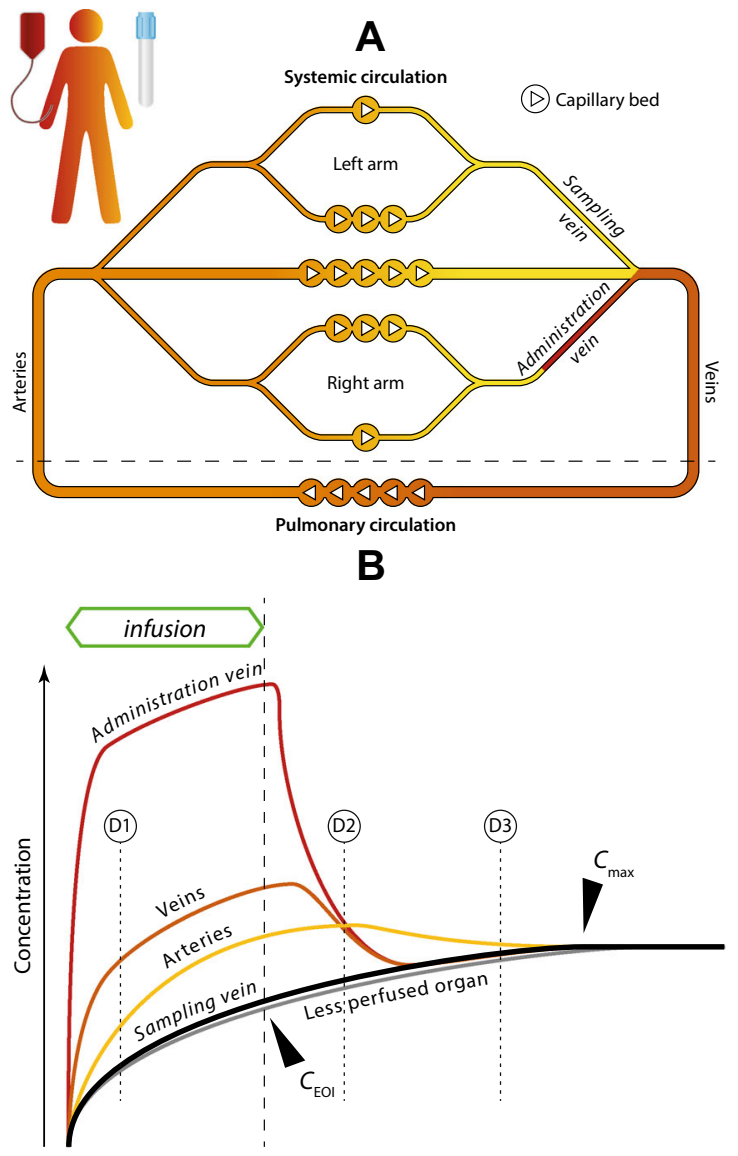

C

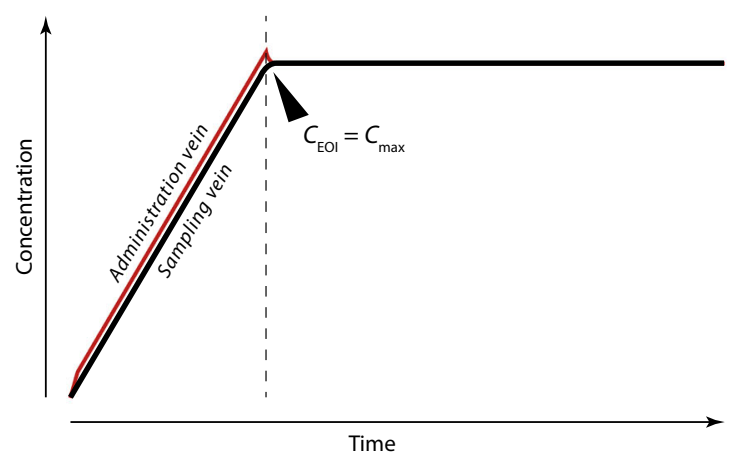

D

administration side

(D1)

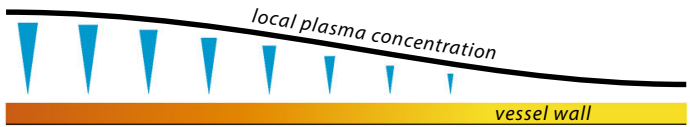

(D2)

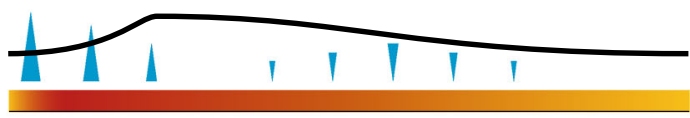

(D3)

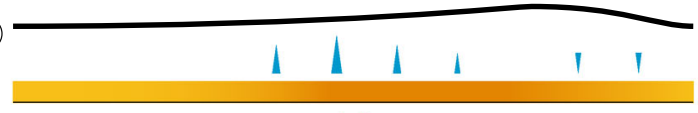

desorption / adsorption
4Fig. 4 Pharmacokinetic profile. Schematic representation of the gradient of biopharmaceuticals over the vascular tree during intravenous administration as a result of endothelial adsorption (a). For illustrational purposes, extravascular distribution and elimination are set to nil. The relative endothelial surface area exposed to the biopharmaceutical in the considered body compartments is indicated by the number of capillary beds. After completion of administration, the gradient slowly dissipates and the relative peak concentration moves along the vasculature to ultimately reach the sampling site (b). In the traditional model, the maximum plasma concentration $\left(C_{\max }\right)$ coincides with the end of infusion $(E O I)(\mathbf{c})$. In d, the vascular tree is conceptualised as a single long vessel and the local situation is depicted at three distinct moments in time. During intravenous infusion, the local plasma concentration is high at the administration side of the vessel, favouring adsorption to the vessel wall, thereby reducing the distal plasma concentration (D1). After EOI, the high local concentration at the administration side drops sharply as a result of recirculation of the relatively low concentration from the sampling side of the vessel. This shifts the balance from adsorption to desorption (D2). As the biopharmaceutical is released from the vessel wall the downstream concentration continues to rise and the relative peak concentration, where adsorption is in equilibrium with desorption, gradually moves alongside the vessel $(D 2, D 3)$. Behind this equilibrium, desorption predominates and ahead adsorption, until finally the gradient has levelled off

Recovery of biopharmaceuticals from the IV line could be incomplete, measuring up to $15 \%$ in the experiments where the pre-filled lines were only flushed, which was unrelated to the biopharmaceutical tested. The only factor that seemingly influenced the net delivery was concentration, with higher concentrations increasing the likelihood of incomplete recovery.

Adsorption to IV material is a well-recognised problem for certain drugs $[42,43]$ and, given existing evidence on biocompatibility, adsorption to the IV line can also explain our observation. An argument against adsorption as the cause is that the reduced recovery was not observed in all experiments (Fig. 3c). Aggregation of the biopharmaceutical within the IV line is another possibility, although the used method to determine drug concentration in the washout also detects drug (protein) aggregates and the drop in protein concentration, therefore, cannot be the result of aggregation.

If the line is flushed following perfusion, drug administration continues after the theoretical EOI for a short time as a result of laminar flow (Fig. 3). However, this only partly explains the 'delay' in $t_{\max }$, as the fraction of the total dose infused during flushing is very small (Fig. 3a). Furthermore, increases in plasma concentration after EOI have also been observed when the line was not flushed, for example with the experimental IgG1 (data on file). Washout of any adsorbed or otherwise retained biopharmaceutical material in the IV line during prolonged flushing did not occur. Thus, flushing of the infusion lines cannot contribute to a delay in $t_{\max }$. 
Concluding, biopharmaceuticals can adsorb to endothelium and be subsequently released into the circulation, which may explain the observation that $t_{\max }$ occurs long after completion of an intravenous administration. Flushing of the infusion lines to complete administration of a biopharmaceutical does not seem to contribute to the delay in $t_{\max }$.

Author contributions The research was designed and analysed by $\mathrm{JR}, \mathrm{JB}$, and MM. The cell-based experiments were designed by MD and $\mathrm{AJZ}$, and performed by MD. All authors interpreted the results and contributed to the writing of the manuscript.

\section{Compliance with Ethical Standards}

Conflict of interest Authors JR, MD, AJZ, MM, and JB declare that they have no conflict of interest.

Funding No funding was received for this study.

Open Access This article is distributed under the terms of the Creative Commons Attribution-NonCommercial 4.0 International License (http://creativecommons.org/licenses/by-nc/4.0/), which permits any noncommercial use, distribution, and reproduction in any medium, provided you give appropriate credit to the original author(s) and the source, provide a link to the Creative Commons license, and indicate if changes were made.

\section{References}

1. Stocks JM, Brantly M, Barker A, Kueppers F, Strange C, Donohue JF, et al. Comparable pharmacokinetic properties of two alpha1-proteinase inhibitors after single therapeutic doses. CHEST J. 2005;128:261S.

2. Martinez-Saguer I, Rusicke E, Aygören-Pürsün E, Von Hentig N, Klingebiel T, Kreuz W. Pharmacokinetic analysis of human plasma-derived pasteurized C1-inhibitor concentrate in adults and children with hereditary angioedema: a prospective study. Transfusion. 2010;50:354-60.

3. Cocchio C, Marzella N. Cinryze, a human plasma-derived C1 esterase inhibitor for prophylaxis of hereditary angioedema. $\mathrm{P}$ T. 2009;34:293-328.

4. Doi T, Muro K, Yoshino T, Fuse N, Ura T, Takahari D, et al. Phase 1 pharmacokinetic study of MK-0646 (dalotuzumab), an anti-insulin-like growth factor-1 receptor monoclonal antibody, in combination with cetuximab and irinotecan in Japanese patients with advanced colorectal cancer. Cancer Chemother Pharmacol. 2013;72:643-52.

5. Tabernero J, Ciardiello F, Rivera F, Rodriguez-Braun E, Ramos FJ, Martinelli E, et al. Cetuximab administered once every second week to patients with metastatic colorectal cancer: a two-part pharmacokinetic/pharmacodynamic phase I dose-escalation study. Ann Oncol. 2009;21:1537-45.

6. Phillips M, Smith W, Balan G, Ward S. Pharmacokinetics of glucarpidase in subjects with normal and impaired renal function. J Clin Pharmacol. 2008;48:279-84.

7. Patnaik A, Kang SP, Rasco D, Papadopoulos KP, ElassaissSchaap J, Beeram M, et al. Phase I study of pembrolizumab (MK3475; anti-PD-1 monoclonal antibody) in patients with advanced solid tumors. Clin Cancer Res. 2015;21:4286-93.
8. de Bono JS, Attard G, Bellmunt J, Droz JP, Miller K, Fléchon A, et al. Open-label phase II study evaluating the efficacy and safety of two doses of pertuzumab in castrate chemotherapy-naive patients with hormone-refractory prostate cancer. J Clin Oncol. 2007;25:257-62.

9. Felip E, Ranson M, Cedrés S, Dean E, Brewster M, Martínez P, et al. A phase $\mathrm{Ib}$, dose-finding study of erlotinib in combination with a fixed dose of pertuzumab in patients with advanced nonsmall-cell lung cancer. Clin Lung Cancer. 2012;13:432-41.

10. Albanell J, Montagut C, Jones ET, Pronk L, Mellado B, Beech J, et al. A phase I study of the safety and pharmacokinetics of the combination of pertuzumab (rhuMab 2C4) and capecitabine in patients with advanced solid tumors. Clin Cancer Res. 2008;14:2726-31.

11. Yoshino T, Yamazaki K, Gotoh M, Nasroulah F, Gao L, Yoshizuka N, et al. Safety and pharmacokinetics of second-line ramucirumab plus FOLFIRI in Japanese patients with metastatic colorectal carcinoma. Anticancer Res. 2015;35:4003-7.

12. Leyland-Jones B, Gelmon K, Ayoub JP, Arnold A, Verma S, Dias $\mathrm{R}$, et al. Pharmacokinetics, safety, and efficacy of trastuzumab administered every three weeks in combination with paclitaxel. J Clin Oncol. 2003;21:3965-71.

13. Baselga J, Carbonell X, Castañeda-Soto N-J, Clemens M, Green M, Harvey V, et al. Phase II study of efficacy, safety, and pharmacokinetics of trastuzumab monotherapy administered on a 3-weekly schedule. J Clin Oncol. 2005;23:2162-71.

14. Wynne C, Harvey V, Schwabe C, Waaka D, McIntyre C, Bittner B. Comparison of subcutaneous and intravenous administration of trastuzumab: a phase $\mathrm{I} / \mathrm{Ib}$ trial in healthy male volunteers and patients with HER2-positive breast cancer. J Clin Pharmacol. 2013;53:192-201.

15. Wisman LAB, De Cock EPM, Reijers JAA, Kamerling IMC, Van Os SHG, de Kam ML, et al. A phase I dose-escalation and bioequivalence study of a trastuzumab biosimilar in healthy male volunteers. Clin Drug Investig. 2014;34:887-94.

16. Wang W. Protein aggregation and its inhibition in biopharmaceutics. Int J Pharm. 2005;289:1-30.

17. Wang W, Nema S, Teagarden D. Protein aggregation-pathways and influencing factors. Int J Pharm. 2010;390:89-99.

18. Lowe D, Dudgeon K, Rouet R, Schofield P, Jermutus L, Christ D. Aggregation, stability, and formulation of human antibody therapeutics. Adv Protein Chem Struct Biol. 2011;84:41-61.

19. Wang W, Wang EQ, Balthasar JP. Monoclonal antibody pharmacokinetics and pharmacodynamics. Clin Pharmacol Ther. 2008;84:548-58.

20. National Institutes of Health. NIH IMAGE. http://rsb.info.nih. gov/nih-image. Accessed 1 Feb 2014.

21. Suarez E, Paredes-Gamero E, Del Giglio A, dos Santos Tersariol IL, Nader H, Pinhal MA. Heparan sulfate mediates trastuzumab effect in breast cancer cells. BMC Cancer. 2013;13:444.

22. Burgess AW, Cho HS, Eigenbrot C, Ferguson KM, Garrett TPJ, Leahy DJ, et al. An open-and-shut case? Recent insights into the activation of EGF/ErbB receptors. Mol Cell. 2003;12:541-52.

23. Chen HX, Gore-Langton RE, Cheson BD. Clinical trials referral resource: current clinical trials of the anti-VEGF monoclonal antibody bevacizumab. Oncology (Williston Park). 2001;15:1017, 1020, 1023-6.

24. Ilan N, Tucker A, Madri JA. Vascular endothelial growth factor expression, beta-catenin tyrosine phosphorylation, and endothelial proliferative behavior: a pathway for transformation? Lab Investig. 2003;83:1105-15.

25. Kim KJ, Li B, Houck K, Winer J, Ferrara N. The vascular endothelial growth factor proteins: identification of biologically relevant regions by neutralizing monoclonal antibodies. Growth Factors. 1992;7:53-64. 
26. Ryser H, Aub JC, Caulfield JB. Studies on protein uptake by isolated tumor cells. II. Quantitative data on the adsorption and uptake of I-131-serum albumin by Ehrlich ascites tumor cells. J Cell Biol. 1962;15:437-49.

27. Curtis ASG. Cell adhesion. Prog Biophys Mol Biol. 1973;27:315-84.

28. Mach H, Gregory SM, Mackiewicz A, Mittal S, Lalloo A, Kirchmeier M, et al. Electrostatic interactions of monoclonal antibodies with subcutaneous tissue. Ther Deliv. 2011;2:727-36.

29. Häcker U, Nybakken K, Perrimon N. Heparan sulphate proteoglycans: the sweet side of development. Nat Rev Mol Cell Biol. 2005;6:530-41.

30. Reitsma S, Slaaf DW, Vink H, van Zandvoort MAMJ, oude Egbrink MGA. The endothelial glycocalyx: composition, functions, and visualization. Pflügers Arch Eur J Physiol. 2007;454:345-59.

31. Boswell CA, Tesar DB, Mukhyala K, Theil FP, Fielder PJ, Khawli LA. Effects of charge on antibody tissue distribution and pharmacokinetics. Bioconjug Chem. 2010;21:2153-63.

32. Bell GI, Dembo M, Bongrand P. Cell adhesion. Competition between nonspecific repulsion and specific bonding. Biophys J. 1984;45:1051-64.

33. Torchilin VP, Trubetskoy VS. Which polymers can make nanoparticulate drug carriers long-circulating? Adv Drug Deliv Rev. 1995;16:141-55.

34. Satulovsky J, Carignano MA, Szleifer I. Kinetic and thermodynamic control of protein adsorption. Proc Natl Acad Sci USA. 2000;97:9037-41.
35. Osterberg E, Bergstrom K, Holmberg K, Schuman TP, Riggs JA, Burns NL, et al. Protein-rejecting ability of surface-bound dextran in end-on and side-on configurations: comparison to PEG. J Biomed Mater Res. 1995;29:741-7.

36. Holland NB, Qiu Y, Ruegsegger M, Marchant RE. Biomimetic engineering of non-adhesive glycocalyx-like surfaces using oligosaccharide surfactant polymers. Nature. 1998;392:799-801.

37. Aird WC. Spatial and temporal dynamics of the endothelium. J Thromb Haemost. 2005;3:1392-406.

38. Reijers JAA, Moerland M, Burggraaf J. Remarkable pharmacokinetics of monoclonal antibodies: a quest for an explanation. Clin Pharmacokinet. 2016;. doi:10.1007/s40262-016-0497-x.

39. Leonard EF, Grabowski EF, Turitto VT. The role of convection and diffusion on platelet adhesion and aggregation. Ann NY Acad Sci. 1972;201:329-42.

40. Einstein A. Über die von der molekularkinetischen Theorie der Wärme geforderte Bewegung von in ruhenden Flüssigkeiten suspendierten Teilchen. Ann Phys. 1905;17:549-60.

41. Erickson HP. Size and shape of protein molecules at the nanometer level determined by sedimentation, gel filtration, and electron microscopy. Biol Proced Online. 2009;11:32-51.

42. Schildt B, Ahlgren T, Berghem L, Wendt Y. Adsorption of insulin by infusion materials. Acta Anaesthesiol Scand. 1978;22:556-62.

43. Smith JC, Davies MC, Melia CD, Denyer SP, Derrick MR. Uptake of drugs by catheters: the influence of the drug molecule on sorption by polyurethane catheters. Biomaterials. 1996;17:1469-72. 